\title{
A modified scheme for biotyping Gardnerella vaginalis
}

\author{
R. BENITO, J. A. VAZOUEZ, S. BERRON, A. FENOLL AND J. A. SAEZ-NIETO
}

Servicio de Bacteriología. Centro Nacional de Microbiología, Virología e Inmunología Sanitarias, Majadahonda, Madrid, Spain.

\begin{abstract}
Summary. A scheme is proposed for biotyping Gardnerella vaginalis, based on detection of hippurate hydrolysis, $\beta$-galactosidase (ONPG) and lipase, and fermentation of arabinose, galactose and xylose. Seventeen biotypes were found among 197 strains from asymptomatic women and patients with bacterial vaginosis (non-specific vaginitis). The distribution of biotypes was similar in both populations but some biotypes were found more frequently in patients. The proposed scheme is compared with those previously described.
\end{abstract}

\section{Introduction}

Several simple schemes have been described for the rapid identification of isolates of Gardnerella vaginalis (Greenwood and Pickett, 1979; Shaw et al., 1981; Piot et al., 1982; Taylor and Phillips, 1983; Benito et al., 1985). In some of these studies strains exhibited considerable phenotypic variation. A preliminary scheme utilising five biochemical tests differentiated 15 biotypes in 100 strains (Benito et al., 1985). In the present study we have evaluated a modification of this scheme incorporating the lipase test (Piot et al., 1984).

\section{Materials and methods}

\section{Collection of specimens}

Vaginal fluid from asymptomatic women and from patients with bacterial vaginosis was collected on calcium alginate swabs and transferred directly on to plates of HBT selective medium (Totten et al., 1982). The latter consists of a basal layer of $7 \mathrm{ml}$ of Columbia agar base, containing colistin $10 \mu \mathrm{g} / \mathrm{ml}$ and nalidixic acid $15 \mu \mathrm{g} / \mathrm{ml}$ (BBL) with amphotericin B $2 \mu \mathrm{g} / \mathrm{ml}$ added after autoclaving, and a $13-\mathrm{ml}$ overlay of the same medium plus $5 \%$ human blood. Proteose Peptone No. 3 (Difco) $1 \%$ was added to both layers before autoclaving and $0.0075 \%$ Tween 80 (BBL) was added to both layers after autoclaving. Inoculated plates were incubated immediately at $366^{\circ}$ in $\mathrm{CO}_{2} 5 \%$ for $48 \mathrm{~h}$.

\section{Characterisations of strains}

Isolates were characterised according to the following criteria (Benito et al., 1985): haemolysis in human-blood agar; absence of haemolysis in sheep-blood agar; hydrolysis of starch; production of $\alpha$ and $\beta$ glucosidase; and sensitivity to trimethoprim (5- $\mu \mathrm{g}$ disk) and to metronidazole (50- $\mu$ g disk).

The 197 strains included in the study came from patients in clinics for the treatment and control of

Received I Jul. 1985; accepted 20 Sep. 1985. sexually transmitted diseases and family planning centres. The strains were isolated from 84 asymptomatic women and from 113 women with bacterial vaginosis.

\section{Biotyping scheme}

Hippurate hydrolysis was tested by the method of Hwang and Ederer (1975) and the lipase test by the method of Piot et al. (1984); $5 \mathrm{~mm} o$-nitrophenyl- $\beta$-Dgalactopyranoside (ONPG) (Sigma) in 1 M PBS was used for the $\beta$-galactosidase test. The reagent was distributed in $0.3 \mathrm{ml}$ portions and inoculated with a loopful $(6 \mathrm{~mm}$ diameter) of the $48 \mathrm{~h}$ cultures of $G$. vaginalis. These were incubated in a water bath at $37^{\circ} \mathrm{C}$ and read at $3 \mathrm{~h}$ and $18 \mathrm{~h}$.

Carbohydrate-fermentation tests were performed in Purple Broth Base (Difco) supplemented with horse serum $5 \%$. The medium was distributed in 5 -ml volumes before autoclaving, inoculated with two loops of a 48-h culture and incubated up to $72 \mathrm{~h}$ at $37^{\circ} \mathrm{C}$ in air. Tubes with doubtful reactions were re-incubated and examined daily for 5 days.

\section{Results}

The biochemical tests used to define the different biotypes were chosen for their simplicity of performance and interpretation, reproducibility and discriminatory capacity. Twenty strains repeatedly tested after numerous subcultures, before and after storage at $-70^{\circ} \mathrm{C}$ in a medium previously described (Benito et al, 1985), gave consistent results.

The biotypes delineated by the six tests are shown in table I. With respect to hippurate hydrolysis and $\beta$ galactosidase activity, the strains were distributed into four groups. Each group was subdivided into biotypes by their fermentation reactions; 15 biotypes were obtained in this way. All biotypes gave a positive reaction with the lipase test and two additional biotypes, $\mathrm{IIa}_{1}$ and $\mathrm{IVa}_{1}$ gave a negative lipase reaction.

As shown in table I, $45.7 \%$ of the strains belonged to group I (hippurate- and ONPG-positive), $24.9 \%$ to group II (hippurate-positive, ONPG-negative), $16 \cdot 2 \%$ to group 
III (hippurate-negative, ONPG-positive) and $13.2 \%$ of the strains to group IV (negative results in both tests). According to the different fermentation patterns and the lipase test, four biotypes were obtained in group I, five in group II, four in group III and four in group IV. The most frequent biotypes were Ia (61 strains), IIa (28), Ib (25) and IIa (17).

The distribution of biotypes according to source is shown in table II. Biotypes IIa, IIa, IIb, IIIa, IIIc and $\mathrm{IVa}_{1}$ were more prevalent in women with vaginosis, whereas biotype IVa was commoner in asymptomatic women. In the populations studied there were no significant differences between the prevalance of different biotypes.

\section{Discussion}

Phenotypic variation in G. vaginalis has been described previously (Greenwood and Pickett, 1979; Shaw et al., 1981; Piot et al, 1982; Taylor and Phillips, 1983; Benito et al., 1985). This led us to consider establishing a biotyping scheme for strain characterisation and epidemiological studies.

In 1984 Piot et al., using a scheme of biotyping of $G$. vaginalis based on the hippurate hydrolysis, ONPG and lipase tests, found eight different biotypes. Previously we described a biotyping scheme using hippurate hydrolysis, ONPG and fermentation of xylose, arabinose and galactose (Benito et al., 1985). In the present study a modified scheme is described in which we have incorporated the lipase test (Piot et al., 1984).

The commonest biotypes encountered amongst our 197 strains were Ia (61), IIa (28) and Ib (25) accounting for $58 \%$ of all isolates (table I). Strains from all groups were isolated more frequently from women with bacterial vaginosis (table II). Although for the majority of biotypes the figures are similar in both groups, biotypes IIa, $\mathrm{IIa}_{1}$, IIb, IIIa, IIIc and $\mathrm{IVa}_{1}$ predominated in vaginosis isolates. Only biotype IVa was very frequent in asymptomatic women; the only two isolates of biotype Id were isolated from this last group. In the populations studied we have not encountered significant differences between the occurrence of the different biotypes.

A comparison of the biotypes defined by our scheme and those obtained by Piot et al. (1984) is shown in table III. Considering only the three biochemical tests employed by these authors: biotypes in group I would correspond to the biotype 1 of Piot, the strains of group II to their biotype 2 and biotype IIa 1 to biotype 5; the strains of group III to biotype 4; those of group IV to biotype 3; and biotype IVa 1 to Piot's biotype 7 . We have not found combinations corresponding to biotypes 6 and 8 .

Although the results of the present study are similar to those found in the other scheme, they differ in the geographical distribution of strains (Piot et al., 1984). Thus, in group I and II the percentages amongst our strains approach those in strains from the USA, except in the case of biotype III $_{1}$ (Piot biotype 5) in which the percentage of our isolates is lower than that found in strains from the USA, Africa and Belgium. In group III, the percentage of biotype 4 found by Piot $e t$ al. in Belgian strains is doubled in our strains. Group IV was isolated in a slightly higher proportion than in isolates from the three other geographical locations (Piot et al., 1984).

The use of three additional sugar fermentation tests in our scheme defined a greater number of biotypes thus increasing the discriminatory capacity. In the absence of reliable methods for serotyping $G$. vaginalis, present

Table I. Biotypes of 197 strains of G. vaginalis

\begin{tabular}{|c|c|c|c|c|c|c|c|c|}
\hline \multirow[b]{2}{*}{ Biotype } & \multirow{2}{*}{$\begin{array}{l}\text { Number } \\
\text { of strains }\end{array}$} & \multirow{2}{*}{$\begin{array}{l}\text { Percentage } \\
\text { of total } \\
(197)\end{array}$} & \multicolumn{6}{|c|}{ Biochemical tests } \\
\hline & & & hippurate & ONPG & lipase & arabinose & galactose & xylose \\
\hline Ia & 61 & \multirow{4}{*}{$45 \cdot 7$} & + & + & + & + & + & + \\
\hline Ib & 25 & & + & + & + & + & + & - \\
\hline Ic & 2 & & + & + & + & - & - & + \\
\hline Id & 2 & & + & + & + & - & - & - \\
\hline IIa & 28 & \multirow{5}{*}{$24 \cdot 9$} & + & - & + & - & - & - \\
\hline $\mathrm{IIa}_{1}$ & 13 & & + & - & - & - & - & - \\
\hline IIb & 4 & & + & - & + & - & - & + \\
\hline IIc & 2 & & + & - & + & + & + & + \\
\hline IId & 2 & & + & - & + & + & + & - \\
\hline IIIa & $17)$ & \multirow{4}{*}{$16 \cdot 2$} & - & + & + & + & + & + \\
\hline IIIb & 7 & & - & + & + & + & + & - \\
\hline IIIc & 3 & & - & + & + & - & - & - \\
\hline IIId & 5 & & - & + & + & - & - & + \\
\hline IVa & 11 & \multirow{4}{*}{$13 \cdot 2$} & - & - & + & - & - & - \\
\hline $\mathrm{IVa}_{1}$ & 8 & & - & - & - & - & - & - \\
\hline IVb & 5 & & - & - & + & + & + & - \\
\hline IVc & 2 & & - & - & + & + & + & + \\
\hline
\end{tabular}


Table II. Distribution of biotypes of $G$. vaginalis by source

\begin{tabular}{c|rcr}
\hline & \multicolumn{3}{|c}{ Number of strains $(\%)$ in subjects } \\
\cline { 2 - 3 } Biotype & total & asymptomatics & bacterial vaginosis \\
\hline Ia & 61 & $28(46)$ & $33(54)$ \\
Ib & 25 & $11(44)$ & $14(56)$ \\
Ic & 2 & $1(50)$ & $1(50)$ \\
Id & 2 & $2(100)$ & \\
Group I & 90 & $42(47)$ & $48(53)$ \\
IIa & 28 & $8(29)$ & $20(71)$ \\
IIa & 13 & $5(38)$ & $8(62)$ \\
IIb & 4 & $1(25)$ & $3(75)$ \\
IIc & 2 & $1(50)$ & $1(50)$ \\
IId & 2 & $1(50)$ & $1(50)$ \\
Group II & 49 & $16(33)$ & $33(67)$ \\
IIIa & 17 & $6(35)$ & $11(65)$ \\
IIIb & 7 & $4(57)$ & $3(43)$ \\
IIIc & 3 & $1(33)$ & $2(67)$ \\
IIId & 5 & $3(60)$ & $2(40)$ \\
Group III & 32 & $14(44)$ & $18(56)$ \\
IVa & 11 & $7(64)$ & $4(36)$ \\
IVa & 8 & $2(25)$ & $6(75)$ \\
IVb & 5 & $2(40)$ & $3(60)$ \\
IVc & 2 & $1(50)$ & $1(50)$ \\
Group IV & 26 & $12(46)$ & $14(54)$ \\
\hline & & &
\end{tabular}

\section{REFERENCES}

Benito R, Sáez-Nieto J A, Berrón S, Vazquez J, Fenoll A 1985 Esquemas de identificación y biotipia de Gardnerella vaginalis. Infectologika 6:54-60 (in Spanish).

Greenwood J R, Pickett M J 1979 Salient features of Haemophilus vaginalis. Journal of Clinical Microbiology 9:200-204.

Hwang M N, Ederer G M 1975 Rapid hippurate hydrolysis method for presumptive identification of group B streptococci. Journal of Clinical Microbiology 1: 114-115.

Piot P, VanDyck E, Peeters M, Hale J, Totten P A, Holmes K K 1984 Biotypes of Gardnerella vaginalis. Journal of Clinical Microbiology 20:677-679.
Table III. Comparison of two schemes for biotyping G. vaginalis

\begin{tabular}{|c|c|c|c|c|c|}
\hline \multirow{2}{*}{$\begin{array}{l}\text { Proposed } \\
\text { scheme }\end{array}$} & \multicolumn{3}{|c|}{ Biochemical tests } & \multirow{2}{*}{\multicolumn{2}{|c|}{ Piot's scheme $\dagger$}} \\
\hline & hippurate & ONPG & lipase & & \\
\hline $\begin{array}{c}\text { Group I }(45 \cdot 7)^{*} \\
(\mathrm{Ia}, \mathrm{Ib}, \mathrm{Ic}, \mathrm{Id})\end{array}$ & + & + & + & 1 & $(26-60)^{*}$ \\
\hline $\begin{array}{l}\text { Group II (18.3) } \\
\text { (IIa, IIb, IIc, IId) }\end{array}$ & + & - & + & 2 & $(8-24)$ \\
\hline IIa $1(6 \cdot 6)$ & + & - & - & 5 & $(16-31)$ \\
\hline Group III $(16 \cdot 2)$ & - & + & + & 4 & (8) \\
\hline Group IV $(9 \cdot 1)$ & - & - & + & 3 & $(4-5)$ \\
\hline $\operatorname{IVa}_{1}(4 \cdot 1)$ & - & - & - & 7 & $(2-8)$ \\
\hline
\end{tabular}

* Percentage of strains.

$\dagger$ Piot et al. (1984)

epidemiological studies will depend on the use of biotyping. To evaluate the usefulness of such schemes, more extensive studies must be performed in various populations to determine the possible association of particular biotypes with bacterial vaginosis.

In view of considerable phenotypic variation between strains of G. vaginalis it is possible that some biotypes may constitute taxons distinct from G. vaginalis. Resolution of this problem must await appropriate genetic studies of such strains.

Piot P, VanDyck E, Totten P A, Holmes K K 1982 Identification of Gardnerella (Haemophilus) vaginalis. Journal of Clinical Microbiology 15:19-24.

Shaw C E, Forsyth M E, Bowie W R, Black W A 1981 Rapid presumptive identification of Gardnerella vaginalis (Haemophilus vaginalis) from human blood agar media. Journal of Clinical Microbiology 14:108-110.

Taylor E, Phillips I 1983 The identification of Gardnerella vaginalis. Journal of Medical Microbiology 16:83-92.

Totten P A, Amsel R, Hale J, Piot P, Holmes K K 1982 Selective differential human blood bilayer media for isolation of Gardnerella (Haemophilus) vaginalis. Journal of Clinical Microbiology 15:141-147. 